\title{
Study and Advance on High Speed Machine Tool Sleeve Bearing with Low Viscosity Lubrication
}

\author{
Li-li Wang \\ College of Mechanical and Electronic Engineering, \\ Shandong University of Science and Technology, Qingdao, \\ China
}

\begin{abstract}
Hybrid sleeve bearings are normally lubricated with high viscosity lubricant, the temperature of oil film increases with the increase of rotating speed. The low viscosity lubricant can decrease the temperature, which is the efficient method to increase the rotating speed of hybrid sleeve bearings. A current situation of the published research works on high speed sleeve bearing with low viscosity lubrication was summarized. The structure of high speed sleeve bearing with low viscosity lubrication was introduced, the effect of wall slip, cavitation, surface roughness, temperature and et al. on bearing properties was analyzed, and the significance of lubrication study for high speed journal bearing with low viscosity lubricant was discussed.
\end{abstract}

Keywords-low viscosity, high speed machine tool, key technology.

\section{INTRODUCTION}

High speed and super-high speed cutting is becoming the main development trend of cutting technology and machine tools. High speed machine tool will play an important role in machinery manufacturing industries, the journal bearing that is the main parts of machine tool spindle system restricts the increase of machining tool rotating speed. Hybrid sleeve bearings are normally lubricated with high viscosity lubricant, the inner fiction of oil film increases and the temperature of oil film increases with the increase of rotating speed, even the burning bearing accidents happen. The low viscosity lubricant can decrease the temperature, get the higher critical speed of burning bearing than high viscosity lubricant, which is the efficient method to increase the rotating speed of hybrid sleeve bearings for the application of low viscosity lubricant. But the application of low viscosity lubricant is less, the study of wall slip, cavitation, surface roughness, temperature and et al. on rotating speed in lubrication is much less, which is key problems that increase the rotating speed of journal bearing. Unless these issues are resolved, journal bearing can better meet the needs of high speed and ultra-high speed machining tool.

\section{Structure OF High SPEed SleEve BeARING With LOW VISCOSITY LUBRICATION}

With the high speed and precision development of rotating machinery, higher requirements have been put forward for the carrying capacity, reliability and stability of sleeve bearing, the structure of journal bearing is more

\author{
Min Wang \\ College of Mechanical and Electronic Engineering, China \\ university of Petroleum, Qingdao, China
}

complicated, and researchers have proposed the hybrid bearing technology with low viscosity medium. Majumdar et al. [1] analyzed the steady state and dynamic characteristics of water-lubricated journal bearings with three axial grooves and showed that load capacity and stability of bearing improve as the groove angles are smaller. Pai et al. ${ }^{[2]}$ studied the non-linear analysis of water-lubricated journal bearings having multiple axial grooves under unidirectional constant load, unidirectional periodic load, and variable rotating load. Cabrera et al. ${ }^{[3]}$ and Geng et al. ${ }^{[4]}$ measured the lubricant film pressure of water-lubricated rubber journal bearings. Dai et al. [5] presented a new water lubrication hybrid journal bearing that had round recess and cooling orifice restrictors for limiting temperature rise on the surface of bush directly and had stepped recesses for enhancing dynamic effect. Zhang et al. ${ }^{[6]}$ studied three dimensional pressure distribution and temperature field of water lubrication hydrostatic journal bearings.

\section{KeY TECHNOLOGY OF SLEEVE BEARING WITH LOW VISCOSITY LUBRICATION}

\section{A. Study of wall slip on bearing performance}

The classical Reynolds equation assumes that lubricant does not slip on the solid interface in the calculation of bearing performance. However, the liquid-liquid or solid-liquid molecules in the interface could not withstand an infinite shear stress, wall slip can occur if shear stress is high enough in theory. Choo et al. ${ }^{[7]}$ proved that Newtonian liquids can slip against solid surfaces that were smooth and lyophobic, and presented that liquid slip can be used to reduce friction in full film. Ma et al. ${ }^{[8]}$ pointed that wall slip can decrease the hydrodynamic response of fluid dramatically. Kalin et al. ${ }^{9]}$ showed the influence of solid-liquid interactions on the coefficient of friction in the elastohydrodynamic lubrication regime. Rao et al. [10] derived the generalized Reynolds equation based on slip length model and analyzed the stability of journal bearing using linear distribution method. Bayada et al. ${ }^{[11]}$ analyzed the theoretical performance of heterogeneous slip/no-slip engineered contacts in order to increase the carrying capacity and decrease the friction drag. Li et al. ${ }^{[12]}$ used the slip length model on the squeeze flow between two rigid spheres and analyzed the effect of slip length on pressure and carrying capacity. 


\section{B. Study of cavitation on bearing performance}

It is necessary to study the cavitation affects, because the presence of cavitation effect affects the stability and carrying capacity of sleeve bearing. The general boundary condition is Reynolds boundary condition and mass conservation boundary conditions. Elrod ${ }^{[13]}$ presented mass conservation cavitation method in 1981, the method considered the mass conservation of oil film boundary. Wang et al. ${ }^{[14]}$ analyzed the characteristics of journal bearing with micro polar fluids considering cavitation effect. Sahlin et al. [15] derived the cavitation algorithm for arbitrary lubricant compressibility, which controlled the full oil film region and the cavitation region by switch function. Shyu et al. ${ }^{[16]}$ analyzed the velocity and temperature distributions, and pressure distribution using the Legendre collocation method, the bulk-flow model and Elord's cavitation algorithm. Braun et al. ${ }^{[17]}$ learned that the cavitation pressure is not common and changed with the axial and circumferential location by experiment. Croper et al. ${ }^{[18]}$ observed that cavitation pressure is not common and the cavitation shape can be acquired by shear mechanism.

\section{Study on thermal effects and non-Newtonian fluids on bearing performance}

In recent years, with the increase of rotating speed and carrying capacity, much damage of bearings is closely related to thermal effects, thermal fluid hydrodynamic lubrication must be used to analyze bearing performance. Roy et al. [19] found that fluid temperature increased, viscosity and carrying capacity decreased because of friction heat. Sharma et al. ${ }^{[20]}$ presented that least oil film thickness decreased, stiffness and damping coefficient and instability speed changed considering thermal effect.

Now lubrication oil is heavy crude oil that contains polymeric additives, lubricant has viscoelastic and shear stress of boundary layer decreases, thus the fluid is not Newtonian fluid and it is non-Newtonian fluids. Garg et al. [21] studied the static and dynamic characteristics of capillary compensated hybrid journal bearing operating with non-Newtonian lubricant.

\section{Study on journal misalignment and inertial force on bearing performance}

In the study of lubrication theory, it is assumed that the flow is laminar, the lubricant inertia effect is small and can be omitted, and the axis of journal and center line of bearing hole are parallel to each other. In the actual work, journal is titled in the bearing bore. The viscosity is very small and Reynolds number is bigger using liquid hydrogen, liquid oxygen, liquid sodium, mercury or water as lubricant, the inertial forces are considered. The turbulent flow is considered with the high speed and super-high speed development of rotating machinery. Ebrat et al. [22] calculated the dynamic characteristics of journal bearing considering bearing structural deformation and journal misalignment. Bouyer et al. ${ }^{[23]}$ tested the journal misalignment effects on hydrodynamic plain journal bearing performances by experiment. Nassab et al. ${ }^{[24]}$ studied the inertia effect on the thermohydrodynamic characteristics of journal bearings.

\section{RESEARCH SIGNIFICANCE}

It is important significance for the structure and properties study of high speed hybrid bearing for low viscosity lubricants, which will decrease temperature rise of machine tool spindle, solve the burning bearing accidents of high speed machine tool, broaden the rotating speed range of machine tool spindle, improve the mechanical processing stability, and acquire the good surface quality of workpiece. Therefore the study of high speed machining tool sleeve bearing will improve the hydrodynamic lubrication theory and the design of low viscosity high speed sleeve bearing, and promote the development of high speed and super high speed cutting technology.

\section{SUMMARY}

With the increase of spindle speed, the study of high speed bearing is becoming more and more important. The low viscosity lubricant can decrease the temperature and get the higher critical speed of burning bearing than high viscosity lubricant, therefore it becomes a hotspot of research. The structure of sleeve bearing with low viscosity lubrication was studied, and analyzed the effect of wall slip, cavitation, temperature and et al. on bearing properties. In future work, the inner mechanism, theory design and et al. need further study, which improves the performance of sleeve bearing and makes it use widely in general engineering and high speed rotating machinery.

\section{ACKNOWLEDGEMENTS}

This work was supported by a grant from National Natural Science Foundation of China (No. 51305242) and National Natural Science Foundation of China (No. 51405513).

\section{REFERENCES}

[1] B C Majumdar, R Pai, D J Hargreaves. Analysis of water-lubricated journal bearings with multiple axial grooves. Proc. IMechE Part J: J. Engineering Tribology. 2004, 218:135-146

[2] R S Pai, R Pai. Non-linear transient analysis of multiple axial groove water-lubricated journal bearings. Proc. IMechE Part J: J. Engineering Tribology. 2008, 222:549-557

[3] D L Cabrera, N H Woolley, D R Allanson, et al. Film pressure distribution in water-lubricated rubber journal bearings Proc. IMechE Part J: J. Engineering Tribology. 2005, 219(2):125-132

[4] T Geng, Q F Meng, N Wang, et al. Experimental investigation of film pressure distribution in water-lubricated rubber journal bearings. Proc. IMechE Part J: J. Engineering Tribology. 2014, 228(4): 397-406

[5] P Dai, Y B Zhang, H Xu. The structure of new journal hybrid bearing for high-speed machine spindle and its performance. Lubrication Engineering. 2009, 34(2):11-14, 24

[6] J Zhang, H S Guo, Ben Niu, et al. Numerical Simulation Study on Water-lubricated Hydrostatic Journal Bearings. Transactions of the Chinese Society for Agricultural Machinary. 2008, 39(6):159-162

[7] J. H. Choo, R. P. Glovnea, A. K. Forrest, H. A. Spikes. A low friction bearing based on liquid slip at the wall. Journal of Tribology, 2007, 129: $611-620$

[8] G J Ma, C W Wu, P Zhou. Wall slip and hydrodynamics of two-dimensional journal bearing. Tribology International 2007,40:1056-1066 
[9] M Kalin, M Polajnar. The effect of wetting and surface energy on the friction and slip in Oil-Lubricated Contacts. Tribology Letters. 2013, 52:185-194

[10] T V V L N Rao. Analysis of single-grooved slider and journal bearing with partial slip surface. Journal of Tribology. 2010, 132(1):1-7

[11] G Bayada, M-H Meurisse. Impact of the cavitation model on the theoretical performance of heterogeneous slip/no-slip engineered contacts in hydrodynamic conditions. Proc. Instn Mech. Engrs Part J: J. Engineering Tribology. 2009, 223:371-381

[12] W-L Li. On the squeeze flow between two rigid spheres with partially wetted surfaces. Proc. Instn Mech. Engrs Part J: J. Engineering Tribology. 2010, 224:195-201

[13] Elrod H G. A cavitation algorithm. Journal of Lubrication Technology, 1981, 103(3):350-354

[14] Xiao-Li Wang, Jun-Yan Zhang, Hui Dong. Analysis of bearing lubrication under dynamic loading considering micropolar and cavitating effects. Tribology International.2011, 44:1071-1075

[15] Fredrik Sahlin, Andreas Almqvist, Roland Larsson, et al. A cavitation algorithm for arbitrary lubricant compressibility. Tribology International. 2007, 40:1294-1300

[16] Shiuh-Hwa Shyu, Yeau-Ren Jeng, Fuli Li. A Legendre collocation method for thermohydrodynamic journal-bearing problems with Elrod's cavitation algorithm. Tribology International. 2008, 41:493-501

[17] M. J Braun, W M.Hannon. Cavitation formation and modelling for fluid film bearings: a review. Proc. IMechE Part J: J. Engineering Tribology. 2010, 224:839-863

[18] M. Groper, I. Etsion. Reverse flow as a possible mechanism for cavitation pressure build-up in a submerged journal bearing. Journal of Tribology. 2002, 124:320-326

[19] L. Roy. Thermo-hydrodynamic performance of grooved oil journal bearing. Tribology International. 2009, 42:1187-1198

[20] S. C. Sharma, Vijay Kumar, S. C. Jain, et al. Study of hole-entry hybrid journal bearing system considering combined influence of thermal and elastic effects. Tribology International. 2003, 36:903-920

[21] H. C. Garg, Vijay Kumar, H. B. Sharda. Thermohydrostatic analysis of capillary compensated symmetric hole-entry hybrid journal bearing operating with non-Newtonian lubricant. Industrial Lubrication and Tribology. 2009, 61(1):11-21

[22] Omidreza Ebrat, Zissimos P. Mourelatos, Nickolas Vlahopoulos, et al. Calculation of journal bearing dynamic characteristics including journal misalignment and bearing structural deformation. Tribology Transactions. 2004, 47:94-102

[23] J. Bouyer, M. Fillon. An experimental analysis of misalignment effects on hydrodynamic plain journal bearing performances. Journal of Tribology. 2002, 124(2):313-319

[24] S A Gandjalikhan Nassab. Inertia effect on the thermohydrodynamic characteristics of journal bearings. Proc. IMechE Part J: J. Engineering Tribology. 2005, 219:459-467 